\title{
Students' Perception toward Mobile Computer-based Physics Laboratory (MCPL)
}

\author{
Nur Hazwani Zakariaa, Fatin Aliah Phang ${ }^{b^{*}}$, Mohamad Bilal Alia, Norazrena Abu Samah ${ }^{a}$ \\ ${ }^{a}$ Faculty of Education, Universiti Teknologi Malaysia, 81310 UTM Johor Bahru, Johor, Malaysia \\ ${ }^{b}$ Centre of Engineering Education, Universiti Teknologi Malaysia, 81310 UTM Johor Bahru, Johor, Malaysia \\ *Corresponding author: p-fatin@utm.my
}

\begin{abstract}
Students learn better with various teaching strategies, related to contextual way and involvement of technology. Low interests among students are caused by students' perception toward Physics and conventional teaching approach. Besides, laboratory malfunctions and destructible apparatus lead to less number of experiments that can be carried out by the students. Students' low achievements in Physics reflect low understandings in concepts and experiments should be able to engage the students' interests in Physics and to attach themselves in science at their tertiary education. Therefore, Mobile Computer-based Physics Laboratory (MCPL) was implemented to 94 Form Four students in Kluang and Kota Tinggi. A survey was carried out using The Instrument to Measure Students' Perception toward MCPL (IMP-MCPL) which consisted of 18 items. The instrument was administered to the students after six weeks of MCPL intervention. The findings showed that $4.3 \%$ of the students had high positive perception. And $95.7 \%$ of the students had middle perception, neither positive nor negative perception. Interviews were carried out to investigate students' perception. Data triangulation was used to analyze students' perception in depth. The MCPL gave positive impact to students' learning, experimenting skills, growing ideas and interacting with other students in the learning process. As a conclusion, MCPL is a way that can be implemented at any place and is convenient for teaching and learning.
\end{abstract}

Keywords: Perception; conceptual understanding; technology; interest; experimenting

(C) 2017 Penerbit UTM Press. All rights reserved

\subsection{INTRODUCTION}

According to [1], students' perception towards science education is centered on perceptions of the teacher and teaching approach, perceptions of the subject content, links and associations with other subject areas and levels of personal interest in the subject. The greatest influence on whether young people found science easy or difficult is centered on perceptions of the style and quality of teaching [1]. According to [1], the perception is that practice in learning science is more enjoyable and makes science easier to learn.

Low interest among students lies in their perceptions towards Physics itself. It is perceived as a boring [2], irrelevant [3] abstract [4], difficult [5], hard and rigorous subject matter [6]. Conventional experiment instruction in Physics laboratory is perceived as a difficult thing for students as the Physicist already disseminate the content of knowledge and it leads to misconceptions in introductory courses in Physics [7]. Laboratory is a need for learning science. A lot of experiments and activities can be carried out to enhance understanding in learning and interacting with laboratory apparatus [8], investigate the condition of matter, to verify the theories and enhance experimenting skills [9], [10]. Laboratory activities and experiments are the most concern element in learning Physics so that students acquire concrete Physics concepts [11] and science process skill [12]. However, students are unable to carry out experiments and learn more theories than experience themselves with experiments.

\subsection{LITERATURE REVIEW}

Forces and Motion is a topic which students face difficulty in making sense of phenomena and lead to abstract [2]. Generally, Physics is perceived as irrelevant [3], difficult [4] or hard and rigorous subject matter [5][6]. Newtonian Laws has been perceived as hard to contextualize in real-life reference. Forces and Motion comprises two sections which is kinematics and dynamic [7]. Kinematics is knowledge explored on an object without considering forces acting on it and it can be abstracted into mathematical functions. Study by [4] states that three from six interviewed students find that Physics is difficult since it uses mathematical formula. It also explores velocity, acceleration, trajectory and linear motion. Dynamic is a knowledge explored on an object with consideration of forces acting on it. Concepts and principles that are related; inertia; momentum; forces in equilibrium; energy; impulse and gravity [7].

An investigation on high school students' use of the concept of force is 'hard' due to the way it is taught and students' cognitive representations [8]. Reports of the overall performance of the candidates show that students' delivering Physics facts and concepts was moderate in Forces and Motion topic [9][8]. The analysis was referred to the SPM Physics Paper 2 in the year 2008 and 2010. A study by [10] states that kinematics becomes problems to students because they have the difficulties in connecting physical concept to its 
corresponding representation and the connections of the representations to the real world. Kinematics usually is represented by graphs of kinematics variable (position, velocity, or acceleration). Students have the difficulties in interpreting the qualities of the graphical representations (slope, intercept, or area under the graph) correspond to the physical concept (velocity, acceleration, or displacement). This is because student learns the concept in discrete unit and not in their real life experience [6]. In suggestion, learning should be taught in contextual way.

A study by [11] investigated university students' perception towards technology-based education. A quantitative study was carried out using 492 participants. For students who lived far from the university area, specifically from rural area, they moved closer to university area or chose to quit. Therefore, a web based instruction was developed to cater the needs of distance education in which the students need not attend formal classes. Web based instruction provided self-schedule, self-paced and self-motivated lessons for students. The study was carried out to investigate the students' perception on web based instruction by analysing their demographic background such as gender, college and computer experience. The respondents were assigned into control group and experimental group. Both groups were administered a test, and questionnaire on attitude and knowledge transfer. The questionnaire was constructed by the researcher and consisted of 31 items and the scales used were strongly agreed (SA) until strongly disagree (SD) and neutral (N) for no opinion. The findings showed that the mean perception was 3.62 and standard deviation 0.38. This is a slight positive as the average scale is 3.00 . As technology based education is costly, technology is perceived for its functionality, reliability and availability of technical support. Negative perceptions from the technology users are their anxieties and frustration, negative attitude towards the course and dissatisfaction. Therefore, studies using technology based education must consider students' competency in using the technology. The students encountered new experiences with this advanced tool of learning which they learnt by themselves. Lack of skills in handling technology can influence the findings of the study and showed that students' involvement in decision making of study choices had positive effects.

Meanwhile, study of perception can be carried out using mixed method study. A study by [12] explored empirical investigation of students' perceptions, rationales and experience on post-secondary school transfers. A mixed model design was used for the study. 358 participants were selected from first year to fourth year students in the universities that they transferred to from another universities. Both quantitative analysis and qualitative analysis was resulted positive decision in students' perception that they involved in decision making in pursuing their studies. They also had better outcomes and the feeling of self-determination. Perception was analysed using the result from the Perceived Control Scale $(\mathrm{M}=22.75, \mathrm{SD}=4.88, \mathrm{n}=95)$ which correlated with interview responses on perceived general $(\mathrm{r}=.41$, $\mathrm{p}<.001)$, academic $(\mathrm{r}=.40, \mathrm{p}<.001)$, social $(\mathrm{r}=.28, \mathrm{p}<.001)$ and overall adjustment $(\mathrm{r}=.42, \mathrm{p}<.001)$. Most commonly, personal reasons included responses based on personal issues such as financial, medical, family reason and specific to individual situations. The responses were coded under the themes such as academic, attachment to home, social, institutional, campus environment, achievement, attachment to university, travel, autonomy and growth, personal and no theme. The highest percentage is academic theme with $54.2 \%$ for attendance at previous institution, personal theme with $47.9 \%$ for departure from previous institution and academic theme with $56.3 \%$ at transferring to current university. The theme of academic was significant in most of the findings. Therefore, it was an important finding for universities to permit students' transfer form one university to another and the study was beneficial in reframing negative perceptions of institutional transfer.

For previous study by [13], it showed a qualitative study involving 119 high school students, 23 teachers and 18 scientists to examine learning activities based on experiences using authentic scientific inquiry and transformational learning. Based on the findings, students' perceptions were different towards scientists and also the perception of themselves as capable of sophisticated science investigation. Students' perceptions towards scientists changed through the use of authentic scientific inquiry. Their earlier perceptions towards scientists were elderly or middle aged and wearing glasses, wearing a white coat, working alone in a laboratory and lacking of science relevance. The perceptions changed as they described scientists as curious, hardworking, cool, busy, regular people, dedicated, patient, resourceful, sleep deprived, casual, relaxed, easy to talk to, knowledgeable, charismatic, down to earth, opened, flexible, flawed, with good work ethics, diligent, brilliant, real, surprisingly with tattoos, humorous, welcoming and normal. The authentic scientific inquiry was implemented using the Students on the Beamline (SotB) program. It was a science outreach program at the Canadian Light Source (CLS) that emphasized project-based learning and the students' experience have been proven to be able to change negative perceptions to positive perceptions and motivated the students to pursue science. Therefore, the study of changing perceptions of students is vital in order to understand how students transform their perceptions that are associated with the science endeavour to value the science enterprise. Therefore, for the study, researcher used mixed method study in order to gain in depth understanding of students' perception toward MCPL in learning Physics secondary school.

Besides, low interest among students related to negative perception toward Physic. Students find that Forces and Motion is a topic that is abstract and they cannot relate the daily phenomena to graphical interpretation and lack of apparatus, broken apparatus and laboratory malfunction lead to low number of carrying out experiments. As a suggestion, for this study, a computer-based experiment is a strategy to connect real motion to its graphical representations using microcomputer-based laboratory [10]. According to [14] ICT becomes a laboratory data logger and visualization and its ability to collect data in vast quantity, high accuracy of measurements, eliminating the drudgery of the data and display, provide students with easy access of different information by letting them play an active role, reinforce students' conceptual learning of Physics concept and develop their understanding of science-technology relationship and it is attractive to larger number of students. Therefore, incorporation computer-based experiment in laboratory can contribute positive impact on students.

Since not all schools have the capacity to accommodate all appliances and provide enough opportunity to do experiment [15]. Some materials are expensive and destructible as time goes by [16]. Government cannot supply all material and apparatus throughout schools. Therefore, they do not have certain usable expensive apparatus. Some schools do not have the latest appliances in teaching science effectively and some school have malfunction school laboratory [17]. These constraints contribute to difficulty in exploratory activity and lack experimenting skills [16]. Conventional experiment instruction in Physics laboratory is perceived as a difficult thing for students as the Physicist already disseminate the content of knowledge and it leads to misconceptions in introductory courses in Physics [18]. Therefore, a mobile computer-based Physics laboratory (MCPL) was introduced as intervention. MCPL was integration of the mobile science laboratory (MSL) and the microcomputer-based laboratory (MBL). 


\subsection{RESEARCH OBJECTIVES}

The objectives of the research was:

(1) To identify the students' perception toward the use of MCPL

(2) To explore the students' perception toward the use of mCPL

\section{Research Questions}

The research questions was:

(1) What is the students' perception toward the use of MCPL?

(2) How students perceived toward the use of MCPL?

\subsection{METHODOLOGY}

\section{Research Design}

A pre-experimental research design was used. The intervention of MCPL took six weeks for the participants to learn Unit 1 until 5 in the learning module. It encompassed MCPL teaching and learning module, the Physics on the Go, a car converted into a service or off-theshelf version mobile laboratory. The mobile laboratory was able to supply electricity to run laptops and tools from PASCO.

PASCO was suitable with Physics secondary school level. Data Studio is a software installed in computers which is capable to show graphs and tables of data on the screen before starting the investigation and the variables can be repeated and manipulated. Interface is used to convert analogue and digital output and display on the screen. Motion sensor is one of the probeware, that sends out short pulses of high-frequency sound (ultrasonic sound) and the time taken for the pulses to bounce off the target and return is recorded [19]. The speed of sound is calculated as the distance between the target and the sensor is varied. Velocities and accelerations can be determined from programming calculation. These quantities can be viewed in form of graphs on the screen after the investigation is completed. Based on Figure 1, an experiment was carried out the respondents in Unit 1. As the trolley moved down the plane, the displacement, velocity, acceleration and graph were displayed on the computer screen. Then, the respondents answered questions in the learning module. After completing five units of learning topic Forces and Motion, they were administered with the Instrument to Measure Perception toward MCPL (IMP-MCPL) and Interview

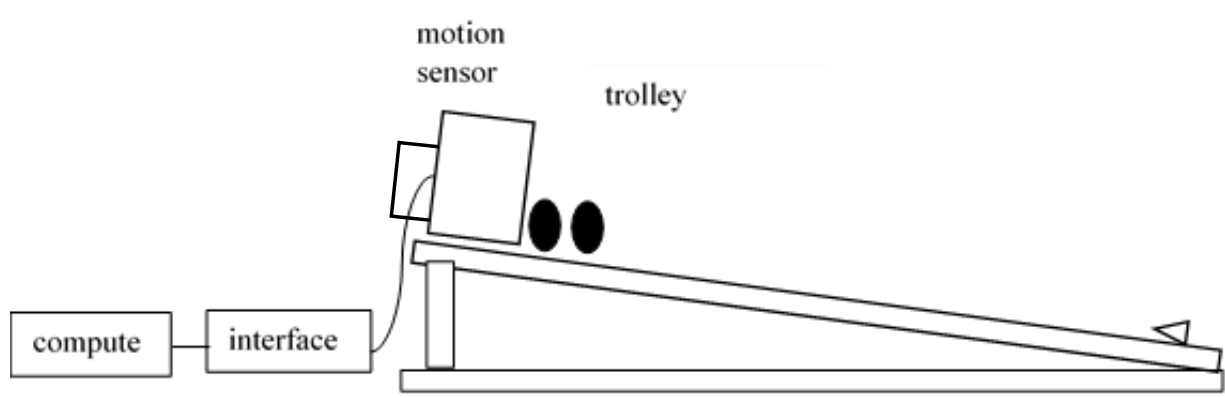

Figure 1 Experiment to investigate the relationship between displacement, velocity and acceleration

\section{Research Instrument and Participants}

The instrument was adapted from [11] with 4 Likert scale from Strongly disagree (SD), disagree (D) and strongly agree (SA). 18 items were used and covered constructs such as learning outcomes, dehumanization, convenience, interactivity and self-motivation and discipline. 94 participants from Kluang and Kota Tinggi were involved in the research. Quantitative data was analyzed using descriptive analysis. According to [20], a content analysis consists of three phase; preparation phase, organizing phase and reporting the analyzing process and the results. For a deductive content analysis, at preparation phase, the researcher select the unit of analysis, and making sense of the data. At organizing phase, the researcher develop data coding according the categories and final phase, reporting the analyzing process and the results involved conceptual map or categories.

\subsection{RESULTS AND DISCUSSION}

As the data from quantitative study was ordinal, the total score was arranged ascendingly and categorized into level of perception. Interview transcripts was analyzed using deductive content analysis [20]. Results from quantitative analysis shows $95.7 \%$ of the respondents had middle perception and $4.3 \%$ had positive perception toward MCPL. Figure 2 shows students' perception toward MCPL. 


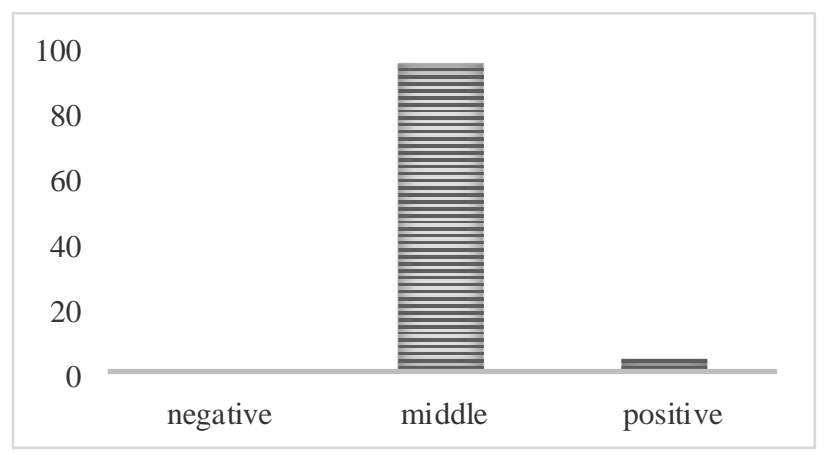

Figure 2 A bar chart for students' perception toward MCPL.

Analysis by items shows the maximum score was 323 for statement, "MCPL offers students adequate interaction with each other" and the lowest score was 158 for statement, "MCPL requires students to be self-disciplined". From the interviews, the respondents stated that MCPL learning module was convenient as the instructions are clearly stated, simple and not confusing with frequency 13.

“..For me, instruction in the module was easy to understand, not confusing. So, it helps from its wordings, example figure provided. We see figures. Then, we just assemble them. For me, the instructions are complete and understandable.."

(category : convenient)

But, ones find that it was quite hard at the beginning of MCPL experiment. Interactivity was good with frequency 10 as the module guide the students step by step and the experiments run smoothly. They also gain the learning as they see how it happened, the difference of concepts, they gain more understanding and apply the knowledge. The MCPL module also have information and experiments implemented gave them more exposure more than usual revision by themselves. Table 1 shows categories and their frequencies for the students; acceptance of MCPL learning module and Figure 3 shows categories that shows how the students perceived the MCPL.

Table 1 Analysis from interview

\begin{tabular}{|l|c|}
\hline Category & Frequency \\
\hline Convenient & 13 \\
\hline Interactive & 10 \\
\hline Develop conceptual understanding & 9 \\
\hline Information & 4 \\
\hline Interesting experiment & 3 \\
\hline
\end{tabular}

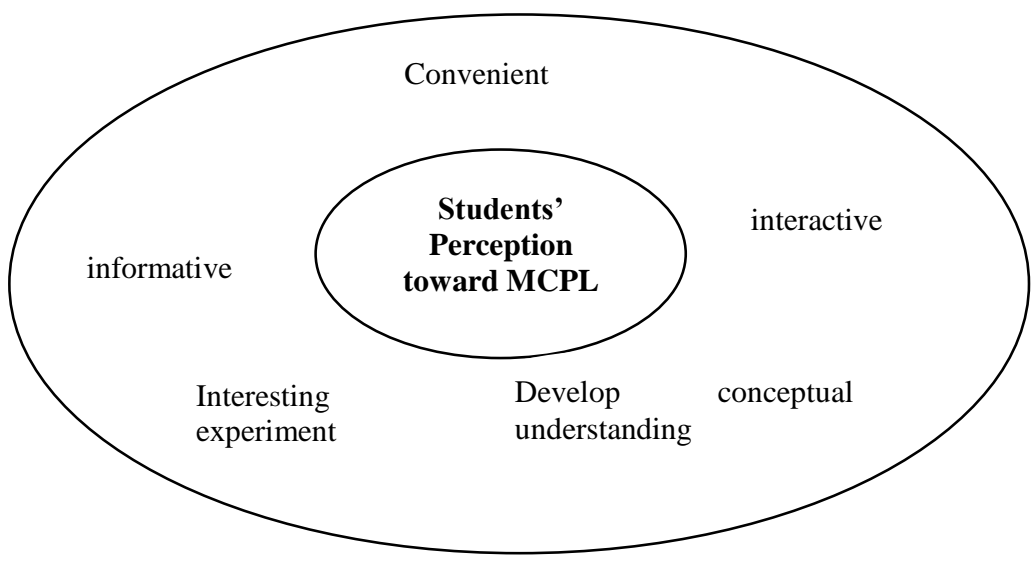

Figure 3 Students' perception toward MCPL

\subsection{CONCLUSION}

MCPL is an alternative teaching strategies and learning that can be carried out by the students. Students can have the use of technology despite of the high cost and areas. They can carry out experiments and the learning process occur as the students carry out experiments and learning module guides them. The research focus on topic Forces and Motion and further research can be done to specified subtopic and suitable sensors for data acquisition. As a conclusion, MCPL is proven able increase conceptual understanding, allow active 
communication to construct knowledge and involve in activities in order to gain concrete experience. As a conclusion, MCPL is proven as able to increase conceptual understanding, allow actual communication to construct knowledge andinvolve in activities in order to gain concrete experience.

\section{References}

A. Williams, J. Furst, K. Cleary, and P. Dastoor (2003). Anthony Williams, John Furst, Kaye Cleary and Paul Dastoor The University of Newcastle, Australia. Engineering Education Conference Proceeding, 21-25.

Abdulilah H. Al-Arfaj. (2001). The Perception of College Students in Saudi Arabia Towards Distance Web-Based Instruction (PhD Thesis). University of Ohio. Curriculum Development Centre. (2005). Integrated Curriculum for Secondary Schools Curriculum Specifications.

H. B. Carlone. (2003). Innovative Science Within and Against a Culture of 'Achievement. Science Education, 87(3), 307-328.

I. A. Ojediran, D. I. Oludipe, and O. J. Ehindero. (2014). Impact of Laboratory-Based Instructional Intervention on the Learning Outcomes of Low Performing Senior Secondary Students in Physics. Scienctific Research, 5(4), 197-206.

L. K. Wee. (2012). One-Dimensional Collision Carts Computer Model and Its Design Ideas For Productive Experiential Learning,. Physics Education, 47, 301-308.

M. G. Wintre and A. S. Morgan. (2009). Transferring Post-Secondary Schools: Student Perceptions, Rationales, and Experiences. Journal of Adolescent Research, 24(6), 726-749.

M. L. Turner. (2005). The Effect of Applying Principles of Reformed Teaching and Learning to an Asynchronous Online Environment on Student Cognition of Physics Concepts in Kinematics (Doctoral Dissertation). University of North Carolina.

Ministry of Malaysia Education (MOE). (2008). Kupasan Mutu Jawapan SPM Fizik 2 4531/2.

Ministry of Malaysia Education (MOE). (2010). Kupasan Mutu Jawapan SPM Fizik 2 4531/2.

Ministry of Malaysia Education (MOE). (2013). Malaysia Education Blueprint 2013 - 2025.

National Foundation for Educational Research (NFER). (2011). Exploring Young People's Views on Science Education.

PASCO. (2005). Pasco Physics Worldwide Catalog and Experiment Guide 2005.

R. Trumper and M. Gelbman. (2001). A Microcomputer-Based Contribution to Scientific and Technological Literacy. Journal of Science Education and Technology. $10(3), 213-221$

R. Trumper. (2006). Factors Affecting Junior High School Students' Interest in Physics. Journal of Science Education and Technology, $15(1), 47-58$.

S. Elo and H. Kyngäs. (2008). The Qualitative Content Analysis Process. Journal of Advanced Nursing, 62(1), 107-115.

T. Chambers. (2014). Three Pedagogical Approaches to Introductory Physics Labs and their Effect on Student (Doctoral Dissertation). University of Arizona.

T. D. Richardson. (2013). Exploring Ontario Grade Ten Students' Decisions To Select Or Reject School Physics (Master Thesis). University of Toronto.

T. Semela. (2010). Who is Joining Physics and Why? Factors Influencing the Choice of Physics Among Ethiopian University Students. International Journal of Environmental \& Science Eduation, 5(3), 319-340.

T. Walker and T. Molnar. (2014). Can Experiences of Authentic Scientific Inquiry Result in Transformational Learning ?. Journal of Transformative Education, 11(4), $229-245$. 